Revue

Revue de l'histoire des religions

de Ihistoire des religions

$3 \mid 2015$

Varia

\title{
Edina BOZOKY, Miracle! Récits merveilleux des martyrs et des saints
}

Paris, La Librairie Vuibert, 2013

Marion de Lencquesaing

\section{OpenEdition}

Journals

Édition électronique

URL : http://journals.openedition.org/rhr/8424

DOI : $10.4000 /$ rhr.8424

ISSN : 2105-2573

Éditeur

Armand Colin

Édition imprimée

Date de publication : 1 septembre 2015

Pagination : 434-435

ISBN : 978-2-200-92993-0

ISSN : 0035-1423

Référence électronique

Marion de Lencquesaing, «Edina воzоку, Miracle ! Récits merveilleux des martyrs et des saints », Revue de I'histoire des religions [En ligne], 3 | 2015, mis en ligne le 21 octobre 2015, consulté le 25 septembre 2020. URL : http://journals.openedition.org/rhr/8424 ; DOI : https://doi.org/10.4000/rhr.8424

Ce document a été généré automatiquement le 25 septembre 2020

Tous droits réservés 


\title{
Edina BOzoKY, Miracle! Récits merveilleux des martyrs et des saints
}

Paris, La Librairie Vuibert, 2013

\author{
Marion de Lencquesaing
}

\section{RÉFÉRENCE}

Edina ВоZоку, Miracle ! Récits merveilleux des martyrs et des saints, Paris, La Librairie Vuibert, 2013, 21 cm, 192 p., 18,90€, ISBN 978-2-311-00257-7.

1 «Un florilège des récits les plus étonnants sur les miracles des saints » (p. 5) : l'ouvrage d'Edina Bozoky s'annonce dès l'introduction comme un ouvrage destiné à susciter la curiosité du lecteur en faisant le choix du plaisant et du surprenant, et qui, malgré l'érudition de son auteur, reste très accessible. Spécialiste de l'histoire religieuse médiévale, Edina Bozoky propose avec Miracle! Récits merveilleux des martyrs et des saints un ouvrage de vulgarisation où se découvrent selon une logique thématique différents récits miraculeux.

2 Le volume présente un choix varié de récits de miracles qui ont eu lieu dans toute la chrétienté antique et médiévale (de l'Afrique à l'Irlande), jusqu'à saint Louis inclus, utilisant des récits essentiellement latins, proposés directement en français. Les sources utilisées par l'auteur sont multiples : des recueils de miracles, de nombreuses Vies de saints, à commencer par le recueil de La Légende dorée (dans l'édition dirigée par Alain Boureau) ou les vies latines des saints irlandais (Vitae Sanctorum Hiberniae éditées par Charles Plummer en 1910), des recueils d'apophtegmes (les trois tomes des Apophtegmes des Pères traduits et compilés par Jean-Claude Guy, publiés aux Éditions du Cerf en 1993, 2003 et 2005), les Écrits apocryphes chrétiens traduits en français (Bibliothèque de la Pléiade, 1997 et 2005), les Acta Sanctorum, ainsi que les articles de critique hagiographique des Analecta Bollandiana.

3 L'authenticité variable des textes n'est pas questionnée : l'emploi du terme "légende » aurait mérité quelques explications, certains saints sont clairement présentés comme 
inventés, à l'exemple de Marguerite (p. 50); l'objet est avant tout de présenter une typologie la plus complète possible d'actes miraculeux. De même pour la disparité des sources: le travail des compilateurs d'apophtegmes au ve siècle ou des hagiographes médiévaux n'a rien de comparable avec celui des érudits bollandistes du xvII ${ }^{e}$ siècle. Cet effet d'aplatissement temporel empêche de voir combien le récit du miracle évolue dans le temps.

Dans une rapide introduction, l'auteur pose les jalons indispensables d'une historicisation simple de la notion de miracle : l'explication étymologique des termes " miraculeux » et "merveilleux » et la présentation du personnel des miracles, les saints, font place à un court développement sur l'évolution de la notion de sainteté et sur l'histoire du genre des recueils de miracles. Le renvoi à différents travaux critiques incontournables (notamment ceux de Jacques Le Goff et d'André Vauchez) vient ouvrir cette introduction volontairement simplifiée.

L'ouvrage se présente en trois parties : miracles opérés par les saints vivants, miracles " entre ciel et terre ", miracles par les reliques miraculeuses.

6 Les miracles des saints vivants sont le résultat d'une logique offensive d'affirmation puis de conversion, les miracles « entre ciel et terre » sont la récompense du sacrifice de la vie du saint ou de ses actes, mettant en avant la fonction d'intercesseur, enfin la troisième partie de l'ouvrage, plus importante, revient sur l'histoire de la croyance dans le pouvoir miraculeux des reliques, qui sont en outre des objets médiateurs entre le fidèle et le saint.

7 Chacune des trois parties développe alors différentes entrées thématiques : citons pour exemple les résurrections, les combats contre le dragon, les miracles météorologiques, les supplices manqués. Chacune de ces entrées est précédée d'un rapide paragraphe introductif présentant le type de miracle qui y sera alors développé de diverses façons, selon différents récits. L'auteur cite longuement les textes traduits, le style hagiographique venant souvent contaminer le style de l'auteur, faisant de ce recueil de récits de miracles un ouvrage très plaisant à lire. Elle fait aussi le choix de récits marquants et souvent spectaculaires: citons la longue mort de saint Georges, qui ressuscite à trois reprises tout en résistant extrêmement bien aux pires tortures (p. 51-54). À ce travail illustratif sont ajoutées quelques remarques qui viennent utilement problématiser le propos. Dans la troisième partie consacrée aux reliques miraculeuses, le chapitre sur les déplacements miraculeux de reliques explique comment les rivalités entre monastères pour leur possession sont souvent à l'origine de ces "déplacements miraculeux» (p.129), autorisant alors le lieu de culte et de pèlerinage. Quelques pages plus loin, un rapide développement explique au lecteur la façon dont la papauté impose à la fin de l'époque médiévale des critères de reconnaissance de la sainteté de plus en plus sévères (p. 141-142). L'auteur rappelle aussi la fonction sociale et politique des reliques miraculeuses (notamment p. 157).

8 La conclusion vient interroger la notion de croyance au miracle, dans le contexte des récits présentés mais aussi plus largement: dès lors que la communication entre les mondes terrestre et surnaturel est reçue, ces récits, par la façon dont ils présentent le miracle comme nécessairement spectaculaire, deviennent un outil persuasif de conversion. Des notes essentiellement bibliographiques et un index des noms de saints viennent compléter l'appareil critique de l'ouvrage; l'auteur a pris le soin de faire suivre le nom de chaque saint de son statut dans la chrétienté (apôtre, martyr, confesseur, vierge, sainte femme), de la date supposée de sa mort et des sources dans 
lesquelles sa vie et ses miracles sont racontés. Une bibliographie d'une page rappelle enfin les grands ouvrages critiques publiés sur le sujet. Renvoyons en complément aux importants travaux de l'auteur: Le Moyen Âge miraculeux. Études sur les légendes et les croyances médiévales (Paris, Riveneuve éditions, 2010), recueil d'articles sur les rapports des hommes au surnaturel et des reliques au pouvoir durant l'époque médiévale; en lien avec ce dernier thème, La politique des reliques de Constantin à saint Louis. Protection collective et légitimation du pouvoir (Paris, Beauchesne, 2006); enfin, les actes du colloque qu'elle a organisé avec Anne-Marie Helvétius en 1997, publiés sous le titre Les reliques. Objets, cultes, symboles (Turnhout, Brepols [« Hagiologia », 1], 1999). 